\title{
INNOVATION WITH A SENSE OF PROPORTION
}

Dear Reader,

The development and marketability of electric vehicles is a subject that has accompanied and occupied us for a long time. Unfortunately however, it has always been and still is being discussed in public largely on the level of philosophical worldview perspectives - and massively propagated. It is high time and long overdue - that this discussion is raised to an objective and technical level and that the issue of electric mobility is debated against a realistic background of what can be made available at a cost that is acceptable to both manufacturers and customers and what the infrastructure might look like. It is also important to consider the timeframe within which relevant market coverage can be achieved at all. Another key point is a consideration of the electricity mix in Germany, as it is an illusion to believe that a relevant number of electric vehicles on the roads would automatically reduce $\mathrm{CO}_{2}$ emissions to a significant extent. With the current German electricity mix, this is definitely not the case. Daimler CEO Dieter Zetsche was heard to say before the German soccer cup final that there was a greater chance of having a million electric cars on Germany's roads than of VfB Stuttgart winning the title against FC Bayern Munich. He hits the nail on the head: expectations and reality can sometime be worlds apart!

The conventional internal combustion engine, whether it runs on gasoline, diesel or gas, will still remain the predominant power unit for the next decade or more, to an increasing extent with electric support in the form of hybrid drive systems. This applies not only to cars. MTZ takes account of this situation and, in this latest issue, takes a close look at innovations in commercial vehicle and industrial engines. ATZlive also has the future of the internal combustion engine on its current agenda: the new International Engine Congress, which it is organising together with the VDI Knowledge Forum on 18 and 19 February 2014, will focus in detail on innovations in internal combustion engines for cars and commercial vehicles. The media partner is, of course, MTZ. You may like to reserve this date in your diary.

Best regards,

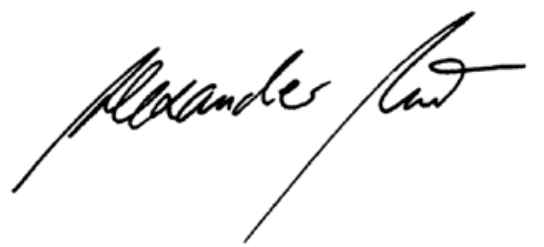

DR. ALEXANDER HEINTZEL,Editor in Chief Wiesbaden, 4 June 2013

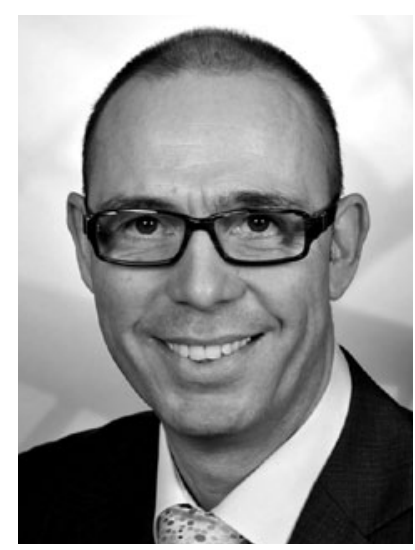

